\title{
Face to face - close range inspection of head vases
}

\author{
D. H. Rieke-Zapp ${ }^{\text {a }}$, E. Trinkl ${ }^{\text {b }}$ \\ a AICON 3D Systems, Scanner Innovation Center, Meersburg, Germany - dirk.rieke-zapp@ aicon.de \\ ${ }^{\mathrm{b}}$ Institute of Archaeology, University of Graz, Graz, Austria, - elisabeth.trinkl@uni-graz.at
}

\author{
Commission II, WG II/8
}

KEY WORDS: Close range, fringe projection, 3D scanning, cultural heritage, head vases

\begin{abstract}
:
Several hundred attic head vases are known worldwide and stored in museums and collections. In 1929, Beazley has categorized twenty groups (A-W) based on stylistic properties and historic methodology. Head vases are assembled in several steps, most important for our comparison is the moulding of the head area. While the other parts of head vases like the size of the handle and the painting can differ significantly from each other, one can notice similarities in the head shapes of the same group. Since molds were used to shape the heads, our initial hypothesis was to perform a quantitative comparison of head shapes based on digital scan data. Comparison of scan data is straight forward and is very similar to quality control and inspection processes in industrial applications. Nonetheless, quality control of approximately 2,500-year-old artefacts that are distributed among several different places is not straight forward. Initial analysis was performed on older scan data. In addition, a high-resolution fringe projection scanner was employed to scan further head vases in additional museums in Germany and Italy. Scan resolution and accuracy of approximately 0.1 $\mathrm{mm}$ in all dimensions were required to reveal differences below $1 \mathrm{~mm}$. All new scans were performed with an AICON SmartScanHE C8. This scanner captures not only shape, but at the same time records color textures which can be employed for presentation or future analyses. Shape analysis results of the head areas do not only confirm that it is likely that the same mold was used for shaping some of the head vases. According to these results, it is also not unlikely that a first generation of larger head vases was used to prepare molds for consecutive generations of head vases that are slightly smaller by 10-15\%. This volume loss resembles closely the volume loss observed after oven-burning of pottery. Scanning will continue to increase the data set for further analyses.
\end{abstract}

\section{INTRODUCTION}

It is an ancient practice to shape a vase in human or animal form. It dates back to the early Mediterranean cultures and lasts until the modern times. In this contribution, we focus on Attic productions of pouring vases (oinochoai) of late archaic and early classical times which bodies are shaped as a human head, mostly female heads (Figure 1). We owe their classification to the fundamental paper of Sir John Beazley, written in 1929 (Beazley, 1929). Since then numerous vessels have been published, but Beazley's groups are still relevant. Beazley categorized the vases in the form of human heads in twenty groups (Group A-W) and a miscellaneous list, according to the depicted figure and the stylistic development of the face, based on an art historic methodology. This classification grounds on a comprehensive knowledge of stylistic development and was criticized in the recent decades because of its subjectivity and lack of transparency. Our analysis focusses on Beazley's groups $\mathrm{N}$ and Q. The largest group of all, the Cook Class (group N), comprises more than 225 known vases worldwide with various human heads in which women's heads are commonest. The small group of the Vienna Class (group Q) includes approximately 14 samples, so far all of them are female heads. The vast majority of the Attic pottery is thrown by the otter's wheel. Concerning the head vases the potters used the same technique only for the upper part of the vessel whereas the head of the head part of the vase was made by two molds, one for the face and a second for the rear; finally some facial details, like eyes and eyebrows, are painted by hand. The process of production interconnects head vases and terracotta figurines.

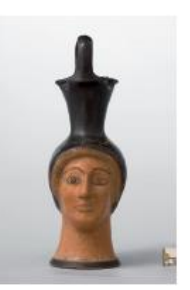

Group N Cook Class Vienna IV998

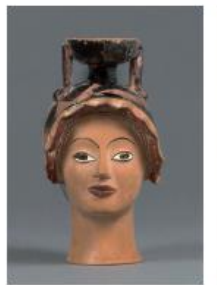

Group B

Epilykos Class

Louvre CA987

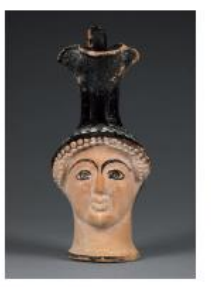

Group O Sabouroff Class Malibu 83.AE.242

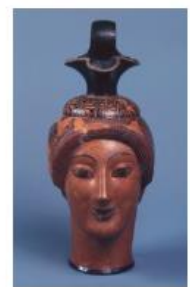

Group C

Charinos Class

St. Petersburg

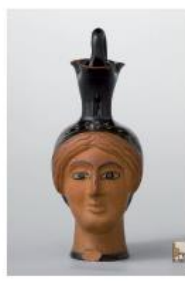

Group Q Vienna Class Vienna IV999

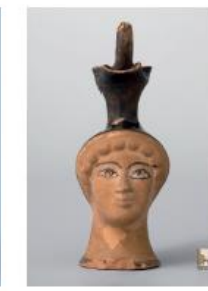

Group ]

Marseille Class Vienna IV4550

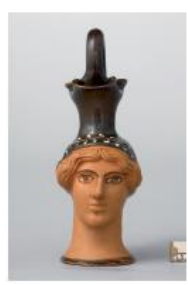

Group T Basel Class Vienna IV1000
Figure 1. Attic head vases of different groups as classified by Bealey (1929). 


\section{MATERIALS AND METHODS}

3D scan models of several vases were selected for comparison. Data was available in PLY and OBJ format and was imported in OptoCat 3D scanning and analysis software (Aicon 3D Systems $\mathrm{GmbH}$, 2017). From Kunstmuseum Wien, some older scans were available in OBJ format. These scans were captured more than five years ago with a Konica Minolta triangulation laser scanner. Additional scans were captured in Antikensammlung Berlin, Antikensammlungen München and recently in Museo Archeologico Bologna with an AICON SmartScan-HE C8 with $450 \mathrm{~mm}$ field of view and resolution of $0.1 \mathrm{~mm}$ (Figure 2).
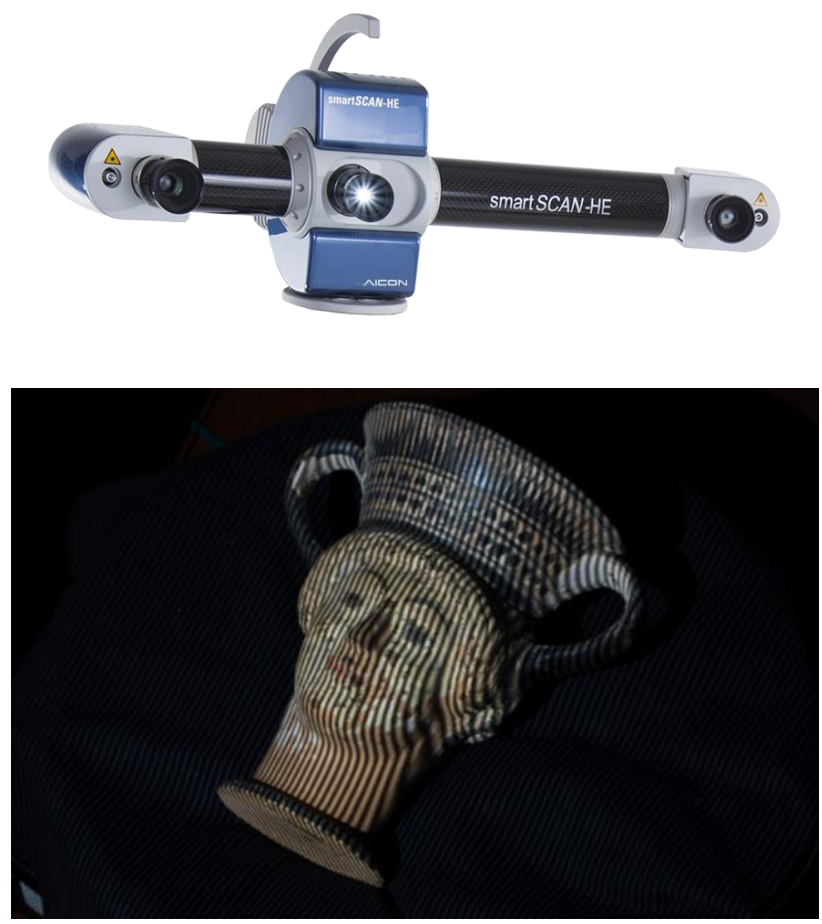

Figure 2. SmartScanHE C8 fringe projection scanner (above). Fringe projection scanning process on attic head vase (below, Antikensammlung Berlin).

Feature accuracy of the system is better than $0.030 \mathrm{~mm}$. The field of view covered the whole vase at a resolution necessary for comparison at the mm to sub-mm level. The accuracy of the system ensured that data acquired at different locations can be compared to each other. Most head vases show very dark and shiny areas in combination with light paintings. This range of material properties (contrast, shininess, etc.) is not straight forward for scanning and required high- dynamic range scanning mode and careful scanner positioning as well as data processing to avoid artefacts in the resulting models. Working with color cameras in the scanner allowed capturing shape and color texture at the same time. In the software OptoCat 3D color textures may be switched on for presentation and artistic interpretation. For shape analysis color textures are not useful, so they can be switched off.

Placing 3D models next to each other allows for a quick comparison of the 3D data (Figure 3). Please note that only 3D models were used for the geometric comparison and that no texture data was used. We are convinced that Beazley's groups are principally correct. Nevertheless, recent computer technology and visualization systems can help to further refine and consolidate the original groups, in respect to chronology and production process. Conventional archaeological methods are inappropriate for these three-dimensional comparisons.

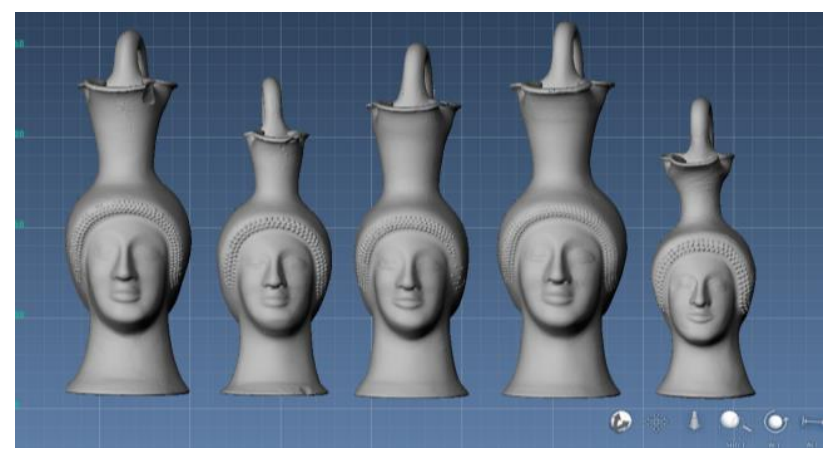

Figure 3. Head vases from Antikensammlung Berlin; F2191, F2192, F2193, F2194, F2195

Shape comparison was performed in AICON's OptoCat software (AICON, 2017). Two candidates were roughly aligned manually and the region of interest that was molded was selected by hand (Figure 4). A fine alignment of the selected areas was performed in OptoCat software which uses an implementation of the iterative closest point algorithm for alignment. After the alignment, the distance between two models was calculated for all vertices and was plotted.

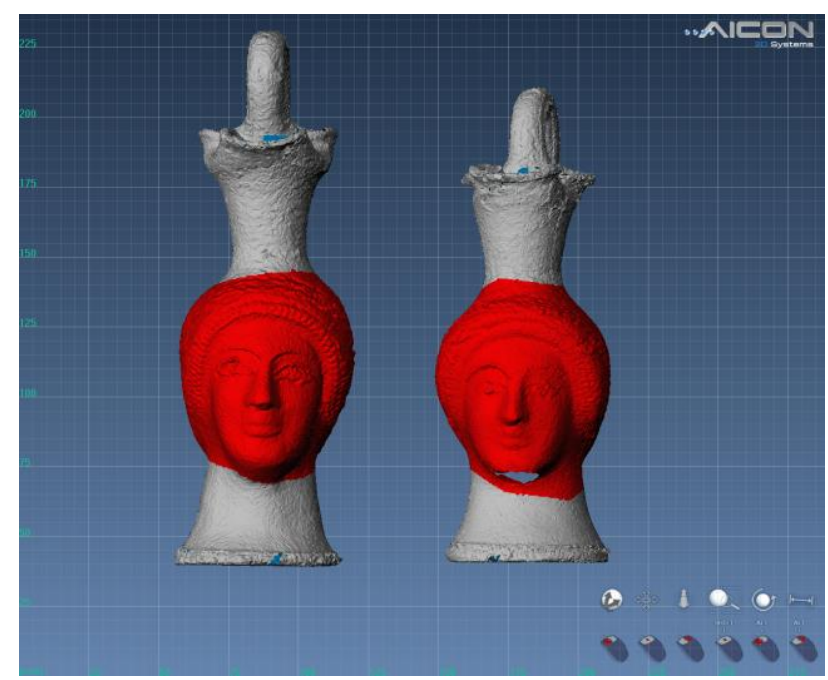

Figure 4. Head vases from Kunstmuseum Wien (1038 and 997). Red areas were selected manually to define regions of interest for alignment.

Placing several head vases of different sizes next to each other, they appear like scaled models of each other. Applying a liner scale factor of 10 to $15 \%$ in $\mathrm{x}, \mathrm{y}, \mathrm{z}$ direction, the digital models were adjusted in size and compared to each other as before.

This procedure was chosen to identify whether head vases that vary in sizes by $\pm 20 \%$ still originate from the same mould. Depending on the properties and the preparation of the clay up to $20 \%$, with an average of approximately $10 \%$ of size differences can be expected after oven burning (Nicholls 1952). 


\section{RESULTS AND DISCUSSION}

Differences of $\pm 1 \mathrm{~mm}$ were assumed to indicate a close correlation between head vases. For several vases deviations were small enough to assume that they originate from the same mold (Figure 5).

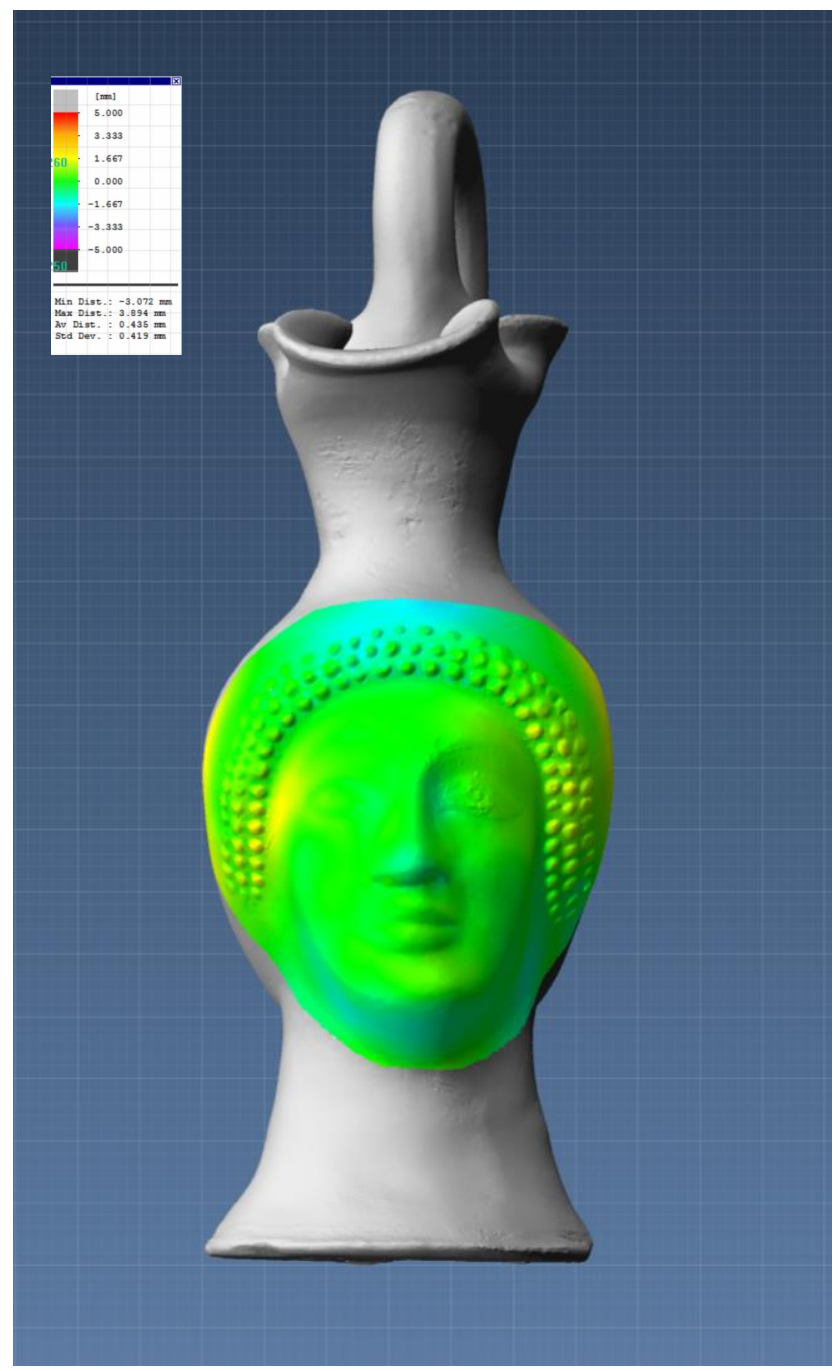

Figure 5. Comparing two head vases from Antikensammlung Berlin (F2195) and Antikensammlung München (SH2745) revealed differences of less than $1 \mathrm{~mm}$ in most the face area and less than $2 \mathrm{~mm}$ of the whole area that was compared.

Comparison of scaled models also revealed small offsets. This variation may be due to shrinking during oven-burning for vases originating from the same mold or may indicate that additional molds were taken from finished vases to produce a set of smaller vases (Figure 6,7).

At the current stage, it is not clear whether material properties caused different sizes of head vases from the same mould or whether different generations of moulds were designed from a single master mould. Closer analysis of material properties may help to answer this question. Another question that cannot be solved is whether different sizes or generations of head vases were in production during the same time.

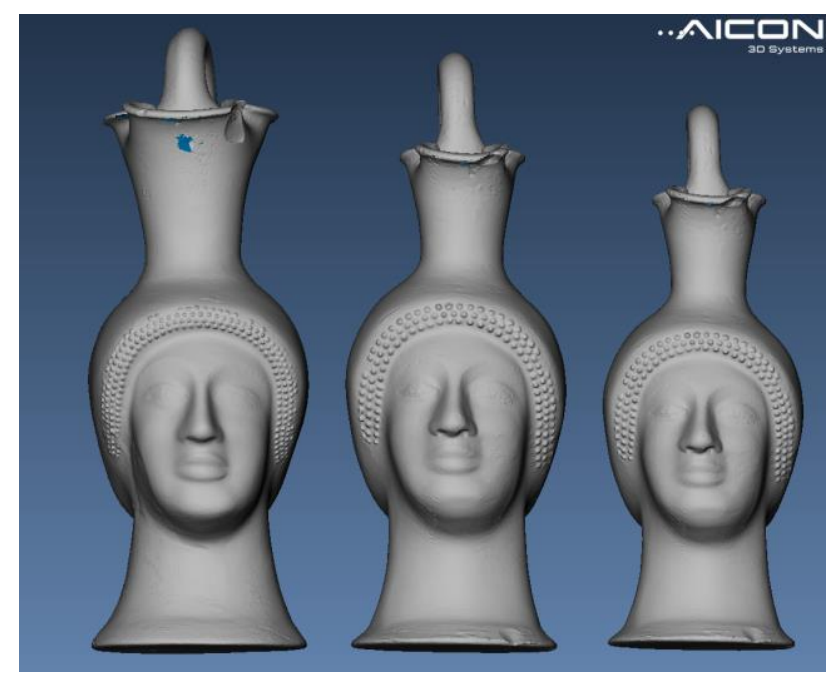

Figure 6. Head vases from Antikensammlung Berlin from left to right: F2191, F2192 scaled to $110 \%$, F2192 in original size.

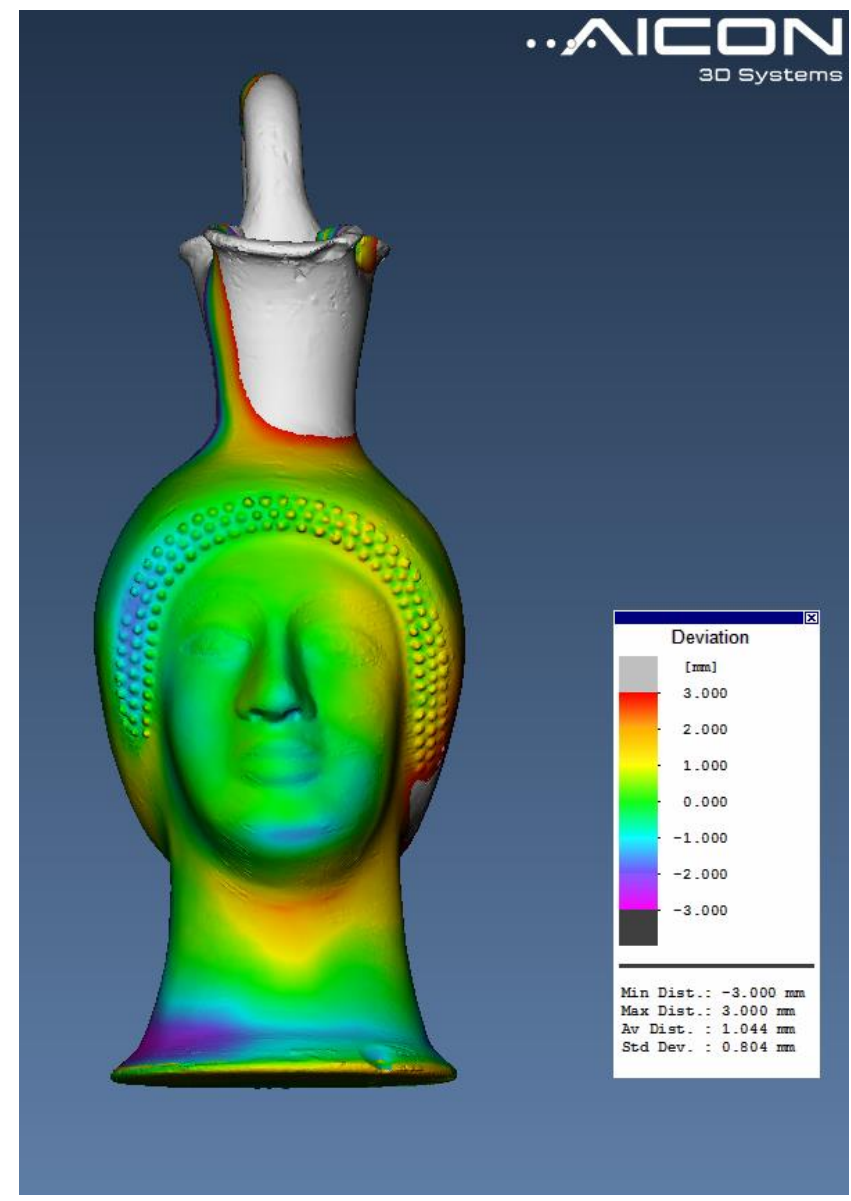

Figure 7. Comparison of Antikensammlung Berlin F2191 and F2192 scaled to $110 \%$. Only the head region was used for alignment. 


\section{CONCLUSION}

Quantitative analysis of digital scans allows for comparison of 2500 year old attic head vases. Several vases appear to originate from the same mold. In addition, scaled version indicate that series or generations of vases exist.

Comparison of head vases is not limited to complete vases or vases that have been restored to completeness. Larger sherds can be compared to head vases given that significant amount of overlap exists (Figure 8).

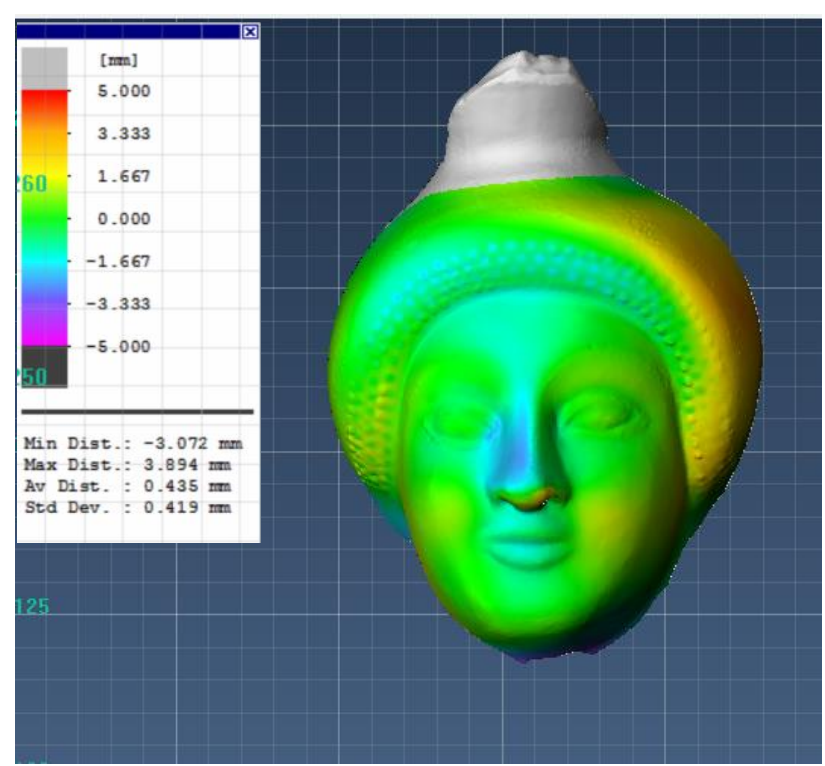

Figure 8. Comparison of Antikensammlung Berlin F2192 (full vase available, c.f. Fig. 6) and F2199 (only the face available).

Working with a digital data sets allows for testing many hypotheses in a fast way, even for large regions. Traditional methods would have to rely on a small number of tactile manual measurements. The current results add to the qualitative analysis performed almost 90 years ago by Beazley as well as observations by archaeologists that formulated similar hypotheses for a long time based on thorough observation. With the help of three-dimensional models, these hypotheses can be tested today.

The authors will continue the scanning of head vases in different collections and museums in the future and will present the digital data in a repository that can be accessed by interested researchers.

\section{ACKNOWLEDGEMENTS}

We acknowledge support by Kunsthistorisches Museum Wien, Staatliche Antikensammlungen München, Antikensammlung Berlin. The project is also supported by the Fritz Thyssen Stiftung.

\section{REFERENCES}

AICON 3D Systems, 2017. OptoCat User Manual, 178p.

Beazley, J. D, 1929. Charinos, JHS 49, 1929, 38-78

Nicholls, R. V., 1952. Type, Group and Series: A

Reconsideration of Some Coroplastic Fundamentals, Annual of the British School at Athens 17, 217-226. 